\title{
Psychosocial Factors That Influence Quality of Life and Potential for Self-Management in Multiple Sclerosis
}

\author{
Judy Ann Wollin, PhD; Gary Fulcher, PhD; Elizabeth McDonald; Nancy Spencer, PhD; \\ Miranda Y. Mortlock, PhD; Maureen Bourne; Rex D. Simmons, PhD
}

Optimizing quality of life (QOL) and self-management in people with multiple sclerosis (MS) is increasingly seen as a worthwhile goal. This study aimed to investigate factors that affect QOL in MS. A large national sample of Australians with MS $(n=1848)$ generated from the Australian Multiple Sclerosis Longitudinal Study completed a survey addressing disease duration and severity, selfefficacy, depression, perceived stress, social support, QOL, and self-management. We tested a model of self-help in which antecedent variables are influenced by mediating variables, which in turn affects outcome variables. In the current study, the antecedent variables were disease duration and disease severity; the mediating variables were self-efficacy, depression, perceived stress, and social support; and the outcome variables were QOL and self-management. We also tested the hypothesis that disease severity, depression, and perceived stress would correlate inversely with QOL and potential for selfmanagement, whereas self-efficacy and perceived level of social support would correlate positively with QOL and potential for self-management. The results indicated that the antecedent variables did not correlate with the mediating variables, with one exception: a negative correlation was found between disease severity and social support. No correlations were found between social support and QOL or self-management. However, significant correlations were found between depression, self-efficacy, stress, and social support and QOL. No correlations were found between either the antecedent or the mediating variables and self-management. The results confirm previous findings of statistically significant correlations between psychosocial factors and QOL. Int J MS Care. 2010;12:133-141.

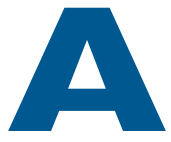

n estimated 18,000 Australians have multiple sclerosis (MS). People with MS have considerably worse health and well-being than the general population, and those living with this chronic disease are in need of various forms of support. ${ }^{1}$ The World Health Organization defines quality of life (QOL) as

an individual's perception of his/her position in life in the context of the culture and value systems in which

From the School of Nursing and Midwifery, Griffith University, Brisbane, Australia (JAW); MS Australia ACT/NSW/VIC, Lidcombe, Australia (GF); MS Australia ACT/NSW/VIC, Melbourne, Australia (EM); Department of Communities, Queensland Government, Brisbane, Australia (NS); Brisbane, Australia (MYM); and Australian MS Longitudinal Study, Canberra Hospital, Woden, Australia (MB, RDS). Correspondence: Rex D. Simmons, PhD, Australian MS Longitudinal Study, Canberra Hospital, PO Box 11, Woden, ACT 2606, Australia; e-mail: Rex.Simmons@act.gov.au.

\begin{abstract}
he/she lives, and in relation to his/her goals, expectations, standards and concerns. It is a broad-ranging concept, incorporating in a complex way the person's physical health, psychological state, level of independence, social relationships, and their relationship to salient features of their environment. ${ }^{2}$
\end{abstract}

The concept of self-management has been defined as "the activities people undertake to create order, discipline and control in their lives." 3 The notion of individuals managing their own conditions more effectively ${ }^{4}$ has significant appeal at a health policy level because it may reduce strain on overburdened health-care systems. There is also considerable evidence that people with MS value and desire self-reliance. In one study, $75 \%$ of people with MS reported that they lacked advice and information on their own care and wanted to enhance this knowledge, ${ }^{5}$ reflecting a commonly held view that health-promoting behaviors and QOL are linked. ${ }^{6}$ With 
regard to MS, however, it is not known how effectively people with MS might adapt to self-management models of care, or precisely what improvements to QOL might result.

People with MS experience a significant decline in their QOL over time. ${ }^{7,8}$ Current research confirms earlier findings that a range of psychosocial factorsincluding coping, mood, self-efficacy, and social support-influence QOL in people with MS and that these factors have a greater impact than biological variables such as weakness or extent of magnetic resonance imaging (MRI) lesions. ${ }^{7-9}$ As a specific example of contributing factors, very high rates of depression are reported over the course of the illness, with up to $50 \%$ of people with MS experiencing severe depression at some time. ${ }^{10}$ Mood not only is related to $\mathrm{QOL}^{6}$ but can reduce the capacity for self-management. ${ }^{11}$ Understanding QOL in MS, a disease with great individual variation, is complicated by the fact that progressive conditions such as MS are "shifting" diseases, with changing symptoms over time. ${ }^{12}$ Furthermore, people with MS report high levels of unmet and expensive health-care needs. In Australia, the average total annual cost of MS per person with the disease is over $\mathrm{A} \$ 37,000$, or nearly US $\$ 32,700 .^{1}$

At the time of the present study, self-management by people with MS in Australia was not a widely implemented policy, but there was considerable interest in the concept at a health policy level. We sought to examine psychosocial factors likely to affect QOL and self-management using Braden's model of self-help ${ }^{13}$ along with relevant published survey instruments: the Perceived Stress Scale, ${ }^{14}$ the MS Self-Efficacy Scale, ${ }^{15}$ the Geriatric Depression Scale-Short Version (GDS-5), ${ }^{16}$ and the Social Support Scale developed for the present study. To measure outcomes, we used the WHOQOL- $100^{2}$ standardized to the Australian population and, as a measure of the potential for self-management, the Therapeutic Self-Care Scale. ${ }^{17}$

In line with predictions from Braden's model, we were guided by the research question "Would perceived stress, self-efficacy, mood, and social support mediate the impact of disease duration and disease severity on QOL and self-management in people with MS?" Moreover, we tested the hypothesis "Disease severity, depression, and perceived stress would correlate inversely with QOL and potential for self-management, whereas self-efficacy and perceived level of social support would correlate positively with QOL and potential for self-management."

\section{Methods}

\section{Sample Recruitment and Characteristics}

The study sample was recruited from the Australian Multiple Sclerosis Longitudinal Study (AMSLS) database. Invitations to participate were mailed to all individuals in the database, and the privacy of respondents was protected by the use of unique identification numbers stored in a relational database. Only the manager of the database had access to identifying material, with the researchers using only coded data. Consenting participants were mailed a composite survey to complete. Consent was implied by completion of the survey. More than $96 \%$ of the participants had been diagnosed by their neurologist or treating physician with definite MS according to the McDonald criteria. ${ }^{18}$ Ethical approval for the study was granted by the ACT Health Human Research Ethics Committee (a National Health and Medical Research Council-constituted, independent ethics committee) and the Human Research Ethics Committee of Griffith University, where the chief investigator is based.

\section{Theoretical Framework}

The theoretical framework of the study was based on Braden's ${ }^{13}$ model of self-help, which predicts that the impact of antecedent factors (eg, severity and duration of illness) on outcome is influenced by mediating factors (eg, perceived stress, self-efficacy, mood, etc.). Thus a mediating variable influences the independent variable, which in turn influences the dependent variable. ${ }^{19} \mathrm{~A}$ review of previous literature on MS yielded the following variables that were considered relevant:

- antecedent factors: perceived severity of illness, duration of illness

- mediating factors: perceived stress, self-efficacy, social support, depression

- outcome factors: QOL as measured by the WHOQOL-100 standardized to the Australian population, and self-management as indexed by the Therapeutic Self-Care Scale

\section{Instruments}

\section{Disease Steps Scale}

The Disease Steps Scale ${ }^{20}$ measures disability across eight levels and correlates very highly with the Expanded Disability Status Scale (EDSS) $(r=0.96)$, but has the advantage of low inter-rater variability so that specialist training in use of the scale is not required. Several stud- 
ies have used patient self-report versions of the Disease Steps Scale. ${ }^{21,22}$ The scale items are presented in Table 1.

\section{Perceived Stress Scale}

The Perceived Stress Scale ${ }^{14}$ is a five-item instrument requiring individuals to rate how disruptive, upsetting, difficult, severe, and stressful they have found the impact of MS on their lives to be compared with other events they have experienced, thus indicating perceived severity of illness. Terry ${ }^{14}$ reported very high internal consistency for this scale (Cronbach $\alpha=0.96$ ). In the present study, responses were indicated on a 5-point Likert scale (eg, "very severe" to "not at all severe"), with higher scores indicating a more positive appraisal of the illness.

\section{MS Self-Efficacy Scale}

The MS Self-Efficacy Scale ${ }^{15}$ is a 14-item self-efficacy measure developed specifically for use with people with MS. "Self-efficacy" refers to the subjective belief that one can overcome the daily challenges that one is faced with. The scale demonstrated high internal consistency (Cronbach $\alpha=0.81)$ and test-retest reliability $(r=0.81$, $P<.001) .{ }^{15}$ In the present study, responses were indicated on a 5-point Likert scale (eg, "strongly disagree" to "strongly agree"), with higher scores indicating a more positive appraisal of self-efficacy. A sample item is "I find that the things I do during the day make me feel happy

\section{Table 1. The Disease Steps Scale (eight steps) with approximate EDSS equivalents}

\begin{tabular}{|c|c|c|c|}
\hline $\begin{array}{l}\text { Self-reported } \\
\text { disease step }\end{array}$ & Description & $\begin{array}{l}\text { Approximate EDSS } \\
\text { equivalent }\end{array}$ & $\begin{array}{l}\text { Broad disability } \\
\text { |evel }^{\mathrm{a}}\end{array}$ \\
\hline 1 & $\begin{array}{l}\text { I may have some mild symptoms, mostly sensory, due to MS } \\
\text { but they do not limit my activity or lifestyle. }\end{array}$ & $0-1$ & Mild \\
\hline 2 & $\begin{array}{l}\text { I have some noticeable symptoms from my MS, but they are } \\
\text { minor and have only a small effect on my lifestyle. }\end{array}$ & $2-3$ & Mild \\
\hline 3 & $\begin{array}{l}\text { MS does interfere with my activities, especially walking. I can } \\
\text { work a full day, but athletic or physically demanding activities } \\
\text { are more difficult than they used to be. I usually don't need to } \\
\text { use a walking stick (cane) or other walking aid, but I might dur- } \\
\text { ing an MS attack. }\end{array}$ & $4-5$ & Moderate \\
\hline 4 & $\begin{array}{l}\text { I can walk about } 8 \text { meters (or } 25 \text { feet) without using a walk- } \\
\text { ing stick (cane) or other walking aid such as a splint, brace, or } \\
\text { crutch, but I may use a walking aid for greater distances. }\end{array}$ & 6 & Moderate (early cane) \\
\hline 5 & $\begin{array}{l}\text { To be able to walk } 8 \text { meters (or } 25 \text { feet), I have to have a walk- } \\
\text { ing stick (cane), a single crutch, or someone to hold onto. I can } \\
\text { get around the house by holding onto furniture or touching the } \\
\text { walls for support. I may use a scooter or wheelchair for greater } \\
\text { distances. }\end{array}$ & 6 & $\begin{array}{l}\text { Moderate } \\
\text { (late cane) }\end{array}$ \\
\hline 6 & $\begin{array}{l}\text { To walk } 8 \text { meters (or } 25 \text { feet), I must have two walking sticks } \\
\text { (canes), two crutches, or a walking frame (walker). I may use a } \\
\text { scooter or wheelchair for greater distances. }\end{array}$ & 6.5 & $\begin{array}{l}\text { Severe } \\
\text { (bilateral support) }\end{array}$ \\
\hline 7 & $\begin{array}{l}\text { My main form of mobility is a wheelchair. I may be able to } \\
\text { stand and/or take one or two steps, but I can't walk } 8 \text { meters } \\
\text { (or } 25 \text { feet), even with crutches or a walking frame. }\end{array}$ & 7 & $\begin{array}{c}\text { Severe } \\
\text { (wheelchair) }\end{array}$ \\
\hline 8 & $\begin{array}{l}\text { I am unable to sit in a wheelchair for more than } 1 \text { hour, and I } \\
\text { spend most of my time in bed. }\end{array}$ & $8-9$ & $\begin{array}{c}\text { Severe } \\
\text { (bedridden) }\end{array}$ \\
\hline $9^{b}$ & $\begin{array}{l}\text { None of the above options describe my MS. I do not have any } \\
\text { mobility problems, but I do have other MS symptoms that limit } \\
\text { my activities and lifestyle. }\end{array}$ & Unclassifiable & $\begin{array}{l}\text { Unclassifiable } \\
\text { (eg, significant cogni- } \\
\text { tive or visual impairment, } \\
\text { overwhelming fatigue, or } \\
\text { significant bowel or blad- } \\
\text { der impairment in an oth- } \\
\text { erwise minimally impaired } \\
\text { patient) }\end{array}$ \\
\hline
\end{tabular}

Abbreviations: EDSS, Expanded Disability Status Scale; MS, multiple sclerosis.

"The broad categories "mild," "moderate," and "severe" were used to organize and present data in the analysis.

bStep 9 respondents were included in the "mild" category for analysis. 
and satisfied." The Cronbach $\alpha$ in the present research was 0.87 .

\section{Geriatric Depression Scale-Short Version (GDS-5)}

The full (30-item) version of the Geriatric Depression Scale (GDS) has been used previously to assess people with MS, ${ }^{23}$ because it avoids items pertaining to somatic symptoms of depression that can be confused with MS symptoms, an important issue when assessing depression in people with MS. The five-item GDS-5 was developed for and validated in geriatric populations ${ }^{24,25}$ and was considered a brief and useful scale for use in the present study because it reportedly avoids the reliance on physi$\mathrm{cal} /$ vegetative symptoms of many depression scales. ${ }^{23-25}$ Significant agreement has been found between depression diagnosis and the GDS-5 $(\kappa=0.81) .{ }^{16}$ In the present study, responses were indicated on a 2-point scale (yes or no), with higher scores indicating the presence of depressive symptoms. A sample question is "Have you felt depressed during the past week?" As a measure of internal consistency, the Cronbach $\alpha$ was 0.80 in the original study ${ }^{16}$ and 0.93 in the present research.

\section{Social Support Scale}

The Social Support Scale is a 13-item scale reflecting day-to-day activities that was developed for this research and used to establish how much support people with MS receive from family and friends. The items address mobility, personal care, meal preparation, and usual activities. In the present study, responses were indicated on a 4-point Likert scale (eg, "never" to "all the time"), with higher scores indicating more assistance provided by family and friends. The Cronbach $\alpha$ was 0.98 in the present research.

\section{WHOQOL-100}

The 100 -item WHOQOL- $100^{2}$ is a well-validated, ${ }^{26,27}$ comprehensive measure of QOL that was designed by the World Health Organization. ${ }^{28}$ It has both general norms for the population (in this case, Australians) and norms for specific diagnostic groups. Unlike diseasespecific QOL measures, this allows comparison with the average citizen, with other diagnostic groups, and with others who have the same condition. ${ }^{28}$ This instrument has been adopted by the Multiple Sclerosis International Federation (MSIF) as the "gold standard" measure for assessing QOL in people with MS. ${ }^{29}$ Items in this selfadministered questionnaire are rated on a 5-point scale and fall into six independent domains: Physical, Psychological, Independence, Social Relationships, Environ- ment, and Spiritual. These domains contain 24 "facets" of four items each, with an additional facet being overall QOL and well-being. The self-administration time of the WHOQOL-100 for "well" people is between 20 and 30 minutes. The internal consistency of the WHOQOL-100 as indicated by the Cronbach $\alpha$ was $0.95 .{ }^{17}$ In the present study, responses were indicated on a 5-point Likert scale (eg,"an extreme amount" to "not at all"), with higher scores indicating a more positive appraisal of QOL. A sample question is "To what extent do you feel that physical pain prevents you from doing what you have to do?"

\section{Therapeutic Self-Care Scale}

The Therapeutic Self-Care Scale ${ }^{17}$ is a 12 -item instrument used to indicate how individuals manage their health, including family assistance and resources needed in the home. The Therapeutic Self-Care index was used as an indicator of potential for self-management in the present study. The instrument's reliability and validity have been established. ${ }^{30}$ In the present study, responses were indicated on a 5-point Likert scale (eg, "not at all" to "very much so"), with higher scores indicating a more positive appraisal of self-management. A sample question is "Can you recognize changes in your body (symptoms) that are related to your illness or health condition?" The Cronbach $\alpha$ has been reported as $0.88^{30}$ and was 0.80 in the present research.

\section{Results}

\section{Respondents}

In December 2006, invitations to complete the survey were mailed to 2630 volunteers with $\mathrm{MS}$, of whom 1848 responded (70\%). As expected with an adult-onset disease, the percentage of respondents younger than 35 years was much lower than the percentage of young people in the general population. The greatest percentage of survey respondents were in the age group of 45 to 54 years (mean, 52.11 years; SD, 11.45 years; range, 27-87 years), and very young and very old people with MS were probably underrepresented in the study. There were 1404 female respondents and 380 males, with 64 participants not reporting gender, yielding a sex ratio of 3.7:1, compared with the expected ratio of $3: 1 .^{1}$ Thus females were overrepresented in this study, although it should be noted that the female-to-male ratio of Australians with MS is increasing. ${ }^{31,32}$ Previous analysis of the AMSLS database, from which $100 \%$ of the current research sample was drawn, indicated a disease type 
distribution (according to the 1996 criteria of Lublin and Reingold) of relapsing-remitting, 55.6\%; secondary progressive, $28.4 \%$; primary progressive, $11.8 \%$; and progressive relapsing, $4.0 \%$. Fifty-three percent of AMSLS database participants were receiving some kind of immunomodulatory therapy. In the last 12 months up to $2003,33 \%$ of participants had relapsed at least once. In the same period, only $34 \%$ of respondents had clinical progression. ${ }^{33}$

\section{Statistical Analysis}

Initially the data were analyzed using summary statistics to identify trends in demographic details. Once the exploratory data analysis was completed, correlations were identified using a bivariate Pearson correlational analysis with a two-tail test. Two strategies were used to manage missing data: when single items were missing, the mean score was inserted, and where the participant had not completed an entire section of the questionnaire, his or her data were not included in the analysis of that section. Because of the large number of survey respondents $(\mathrm{n}=1848)$, there was a tendency for even relatively low correlation coefficients to become statistically significant. Thus, in order to reduce the risk of overstating the findings, only correlation coefficients greater than 0.6 or less than -0.6 have been reported, and all reported correlations were significant at the .01 level unless otherwise stated.

In order to simplify the analysis of correlations between antecedent factors and mediating factors by disease severity, the 1628 respondents' data consisting of eight levels of Disease Steps were stratified into three MS severity categories: "mild" ( $\mathrm{n}=756 ; 46.44 \%$ of participants), "moderate" ( $\mathrm{n}=597 ; 36.67 \%)$, and "severe" $(\mathrm{n}=275 ; 16.89 \%)$. The correlation between the original eight-level scale of self-reported MS severity and the simplified three-level scale used for data analyses was 0.94 . The self-reported Disease Steps Scale used in the present study is shown in Table 1, with approximate EDSS equivalents.

\section{Correlations with Severity of Illness}

The antecedent factor severity of illness correlated moderately with the mediating factor social support $(r$ $=0.60)$. Using the \pm 0.6 correlation criterion for significance, social support did not correlate with any of the WHOQOL-100 measures of QOL, including the facet overall QOL and well-being. No other correlations of severity of illness with mediating factors (depression, perceived stress, or self-efficacy) were found (Figure 1).

One-way analyses of variance (ANOVAs) were conducted to determine whether there were significant differences between the means of the three MS severity groups for QOL and self-management. A difference in the WHOQOL-100 facet overall QOL and well-being was observed $\left(F_{2,1578}=122.97, P<.001\right)$. Post hoc Scheffé tests indicated that respondents with mild MS (mean, 15.18; SD, 3.19) reported significantly higher QOL than those with moderate MS (mean, 12.79; SD, 3.26) and those with severe MS (mean, 12.17; SD, 3.77). Respondents with moderate MS also reported higher QOL than those with severe MS. No significant correlations were found between disease severity and self-management as measured using the Therapeutic Self-Care Scale.

\section{Correlations with Duration of Disease}

The antecedent factor duration of disease ranged from 3 to more than 36 years. Using the conservative

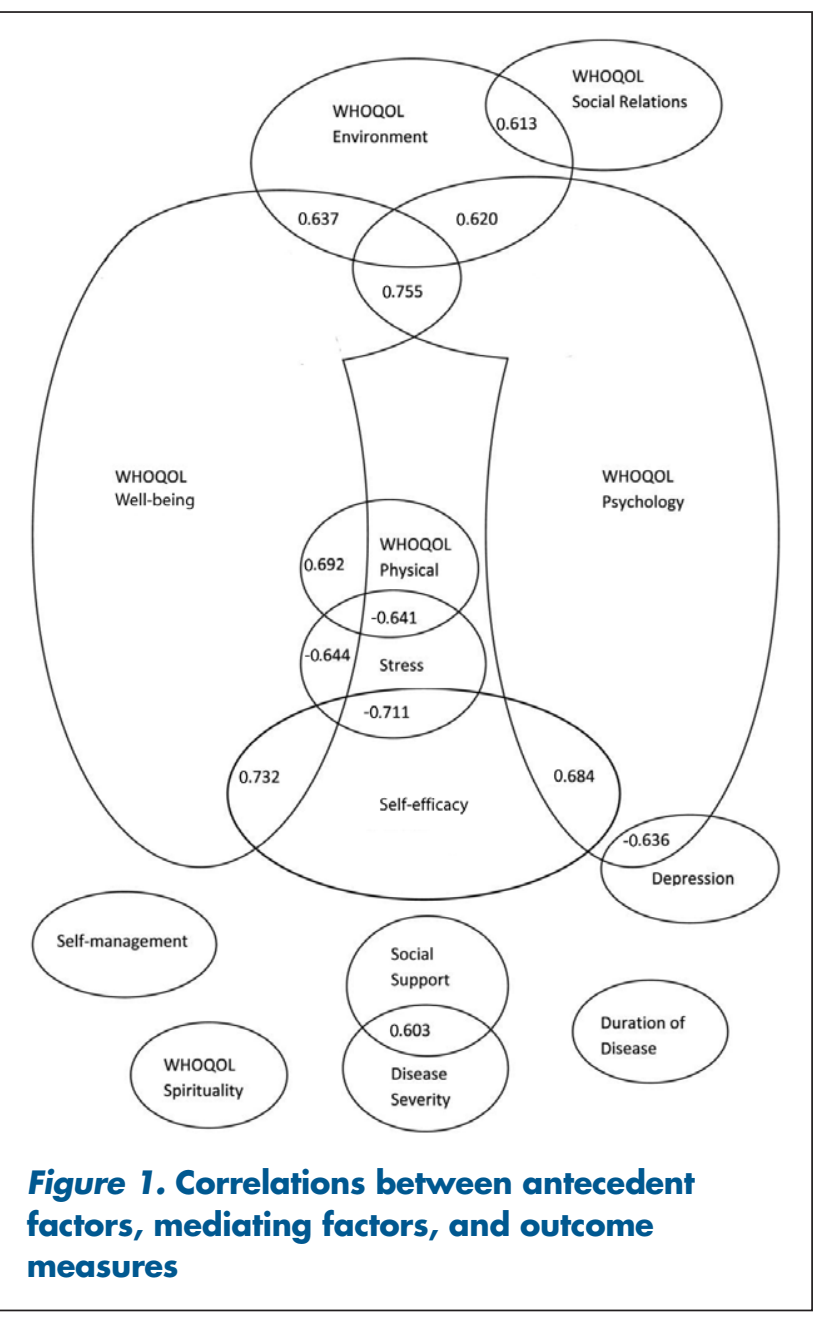


\pm 0.6 correlation criterion for significance, no significant correlations were found between duration of illness and the mediating variables depression, perceived stress, and self-efficacy. Moreover, no significant correlations were found between duration of disease and the outcomes QOL and self-management. However, deterioration in variables associated with QOL (the WHOQOL-100 domains of Physical, Psychological, Independence, Social Relationships, Environment, and Spiritual and the facet overall QOL and well-being) occurred when participants transitioned from mild MS to moderate MS (Figure 2).

\section{Correlations with QOL and Self-Management}

In line with predictions from Braden's model that antecedent factors are influenced by mediating factors, we hypothesized that in people with MS the "negative" mediating factors depression and perceived stress would correlate inversely with QOL and self-management, whereas self-efficacy and level of social support would correlate positively with QOL and self-management. A significant negative correlation was found between depression and the outcome measure WHOQOL-100 Psychological domain (-0.636). Significant negative correlations were also identified between perceived stress and the WHOQOL-100 Physical domain (-0.641) and the facet overall QOL and well-being (-0.644). Positive correlations were observed between self-efficacy and the WHOQOL-100 Psychological (0.684) and Physical (0.598) domains and the facet overall QOL and well-being (0.732). Thus the hypothesis that perceived stress would correlate inversely with QOL and that self-efficacy would correlate positively with QOL was supported. However, no significant correlations were found between Therapeutic Self-Care as an index of self-management and perceived stress, depression, or self-efficacy (Figure 1).

\section{Correlations Among Mediating Factors}

A significant inverse correlation between the mediating factors perceived stress and self-efficacy $(-0.711)$ was identified even though this did not address the research question or hypothesis.

\section{Correlations Among Outcome Measures}

One important finding of this study is that key outcome factors were found to correlate even though this did not address the research question or hypothesis. The WHOQOL-100 facet overall QOL and well-being correlated with WHOQOL-100 Psychological (0.755), Physical (0.692), and Environment (0.637) domains. The WHOQOL-100 Environment domain in turn correlated with the domains Social Relations $(0.613)$ and Psychological (0.620) (Figure 1). This reflects the Cronbach $\alpha$ for the WHOQOL-100 domains in this research (0.753).

\section{Discussion}

This study set out to determine the psychosocial factors that influence QOL and potential for self-management in people with MS using a composite instrument that addressed disease severity and duration, depression, perceived stress, self-efficacy, social support, self-management, and QOL.

The antecedent variables disease severity and disease duration did not correlate with either QOL or selfmanagement using the conservative criterion of at least \pm 0.6 correlation coefficient for significance. However, QOL was found to vary significantly with disease severity (categorized as mild, moderate, or severe disability) using ANOVA and post hoc tests. Thus, several aspects of QOL_as measured using the WHOQOL-100, 
including Physical, Psychological, Independence, and Social Relationships domains and the facet overall QOL and well-being - deteriorated with progression of disease from mild to moderate disability levels (Figure 1). Confavreux et al. ${ }^{34}$ established, with a sample of 1844, that the median time from the onset of MS to the assignment of a score of 4 on the EDSS was 8.4 years $(P$ $=.05$ ). Given that life expectancy remains largely unaffected by MS, diagnosis commonly occurs around age $30,{ }^{1}$ and the impact of the disease is lifelong, the first decade of the disease constitutes the early phase of MS. The deterioration in QOL indicates that psychological support services for people with MS may be needed relatively early in the disease trajectory.

This study found no correlations between the antecedent factors disease severity and disease duration; the mediating factors perceived stress, self-efficacy, mood, social support, and depression; and the outcome measure self-management. The Therapeutic Self-Care Scale used to assess self-management in this study addresses how individuals manage their health, including family assistance and resources needed in the home. ${ }^{17}$ For this sample the critical variables that correlated with QOL were self-efficacy, stress, physical well-being, and psychological well-being. These results confirm earlier findings suggesting that self-efficacy is an important predictor of QOL. ${ }^{6}$ The results of this research, consistent with those of other studies, ${ }^{35}$ indicate that people with MS may benefit from strategies that enhance self-efficacy, which in turn is likely to have a positive impact on QOL.

The question arises, "Is there a link between selfmanagement by people with MS and QOL?" The evidence is mixed. Self-management has been defined as "the activities people undertake to create order, discipline and control in their lives,"3 but the terms self-management, coping, ${ }^{36}$ and autonomy ${ }^{37}$ are currently used to address the same concept. An evidence-based education program found improved autonomous decision making in people with MS, but no difference in QOL was observed between the control and intervention groups. ${ }^{37}$ Self-management of self-catheterization had both a positive and a negative impact on QOL. ${ }^{38}$ Chiovetti ${ }^{39}$ has suggested that self-management requires a foundation of sound information and that information literacy is directly linked to a person's capacity for self-management and QOL. Kralik, ${ }^{40}$ however, has suggested that self-management has very few demonstrated benefits and that a person's ability to manage a chronic disease changes over time, as do the factors likely to influence QOL.

In this study we reasoned that the potential for selfmanagement would rely on variables similar to those for QOL in Baden's model. However, the prediction that similar psychological, social, and physical variables would correlate with outcomes of QOL and selfmanagement was not sustained. This could be due to a number of factors. First, the Therapeutic Self-Care questionnaire may not have been an adequate index of selfmanagement, although this is unlikely given that it consists mainly of questions related specifically to managing one's own condition, including knowledge of medication, symptom management, and daily activities. ${ }^{17} \mathrm{It}$ seems likely, therefore, that the psychological, social, and physical variables related to QOL and self-management may be significantly different and need further investigation. On the other hand, the lack of correlation of such factors as disease severity and depression with self-management can be viewed as a positive sign, because such factors may have less influence than previously suspected on effective self-management by people with MS.

The present study has generally confirmed and extended previous findings ${ }^{7,8,34,41}$ on the relationship between depression, perceived stress, self-efficacy, and QOL using the WHOQOL-100 questionnaire. For example, the WHOQOL-100 facet overall QOL and well-being correlated positively with self-efficacy (0.732) and negatively with perceived stress $(-0.644)$ and depression $(-0.533$, just below the conservative criterion of -0.6 level of significance in the present study). Of the various WHOQOL-100 domains, scores on the Psychological domain correlated positively with self-efficacy (0.684) and negatively with depression (-0.636), as might be expected. In addition, there was a strong negative correlation between self-efficacy and perceived stress $(-0.711)$, indicating that people with MS who have a strong sense of being able to cope with the difficulties associated with having MS report less stress. Previous research has suggested that variables such as self-efficacy and social support may play a positive role in countering the effects of existing disability to increase QOL, ${ }^{8}$ and overall our results may be interpreted to support this finding.

Results from the present study also partially confirm the work of Koch and colleagues, ${ }^{42}$ who found that three key factors were associated with reduced QOL in people with MS: more pervasive symptoms, greater 
role disturbance, and lower educational levels. Similarly, Gulick ${ }^{43}$ found that "living with spouse," "mental/ emotional symptoms," "pain," and "recreating/socializing functions" correlated with QOL and accounted for $61 \%$ of the variance in the "Life Situation Survey." The significance and presence of mood disorders in people with MS is well established. Sadovnick et al. ${ }^{10}$ found that the age-corrected cumulative risk for depression among the MS index cases was $50.3 \%$ by age 59 years. The presence of depression and anxiety has been found to amplify the impact of disability in people with a chronic comorbid condition. ${ }^{10}$ In addition, major depression in people with MS that is left untreated is not self-limiting, while people with MS who are treated with medications and cognitive behavioral therapy tend to do better than those who receive either intervention alone. ${ }^{44}$ Early assessment and interventions to address the psychosocial aspects of living with MS are essential in order to maintain QOL in these people. ${ }^{45}$

\section{Study Limitations}

The strengths of the present study include its large sample size, the use of a generic QOL instrument to allow comparisons with the general population, and the use of published scales for data acquisition and analysis. The limitations of the study include the self-reported nature of the data, although this is countered somewhat by the use of published, validated measures for the psychosocial variables investigated. Another limitation is the apparent overrepresentation of females in the sample (female-to-male ratio of 3.7:1, compared with an expect-

\section{Prectice Points}

- Psychosocial factors correlate more strongly than disease duration or disease severity with quality of life (QOL) in MS.

- People with MS report deterioration in QOL when they transition from mild to moderate disease.

- In order to optimize their QOL, people with MS should be assessed for depression, perceived stress, self-efficacy, and social support regardless of the time since diagnosis.

- "Early" assessment before the progression of disability will help maintain positive contributors to QOL such as self-efficacy and psychological health and may limit the impact of negative factors such as stress and depression. ed 3:1) and underrepresentation of very young and very old people with MS. Finally, the use of only one scale to index potential for self-management, the Therapeutic Self-Care Scale, could have biased our results; thus, additional self-management indices and the influence of psychosocial factors other than those reported here require investigation in future studies.

\section{Conclusion}

The results of this study confirm previous findings ${ }^{7,8,34,41}$ and show that deterioration in QOL occurs when people with MS transition from mild to moderate disease severity. Future longitudinal research confirming these results is required.

In order to optimize QOL of people with MS, routine assessment that addresses depression, perceived stress, self-efficacy, and social support should be incorporated into routine care regardless of the time since diagnosis. "Early" assessment before the progression of disability will help maintain positive contributors to QOL such as self-efficacy and psychological health and may limit the impact of negative factors such as stress and depression. The assumption that QOL is likely to be good based on either disease duration or severity is flawed and results in people with MS not receiving the health care and support they need in order to maintain QOL.

Acknowledgments: We acknowledge the contributions of Wendy Chaboyer, PhD, Elizabeth Kendall, PhD, and Jillian Chalker, $\mathrm{PhD}$, in the early development of the research. We are also grateful to the volunteers at MS Australia, ACT Branch, for survey collation and mailing assistance. Finally, we gratefully acknowledge the essential contribution made by the survey respondents from the Australian Multiple Sclerosis Longitudinal Study.

Financial Disclosures: The authors have no conflicts of interest to disclose. This study was funded by a grant from Griffith University and in part by MS Research Australia through corporate donations, including from Perpetual Trustees Philanthropic Division, Deloitte Australia, Bayer-Schering, Biogen-ldec, Merck-Serono, and SanofiAventis.

\section{References}

1. Access Economics. Acting positively: strategic implications of the economic costs of MS in Australia. http:www.accesseconomic.com.au/ frameset.htm. Published 2005. Accessed September 25, 2005.

2. Murphy B, Herrman H, Hawthorne G, Pinzone T, Evert H. Australian WHOQOL Instruments: User's Manual and Interpretation Guide. Melbourne, Australia: Australian WHOQOL Field Study Centre; 2000. http://www.psychiatry.unimelb.edu.au/qol/whoqol/instruments/ manual.pdf. Accessed September 25, 2005.

3. Kralik D, Koch T, Price K, Howard N. Chronic illness self-management: taking action to create order. J Clin Nurs. 2004;13:259-267.

4. Clark NM, Janz NK, Dodge JA, et al. Self-management of heart disease by older adults. Research on Aging. 1997;19:362-382. 
5. Wollin J, Sato A. An international comparison of caregiver burden in multiple sclerosis. Australas J Neurosci. 2001;14:21-25.

6. Stuifbergen AK, Seraphine A, Roberts G. An exploratory model of health promotion and quality of life in chronic disabling conditions. Nurs Res. 2000;3:122-130.

7. Beiske AG, Naess $\mathrm{H}$, Aarseth $\mathrm{JH}$, et al. Health-related quality of life in secondary progressive multiple sclerosis. Mult Scler. 2007;13: 386-392.

8. Lobentanz IS, Asenbaum S, Vass K, et al. Factors influencing quality of life in multiple sclerosis patients: disability, depressive mood, fatigue and sleep quality. Acta Neurol Scand. 2004;1 10:6-13.

9. Mitchell AJ, Benito-León J, González JM, Rivera-Navarro J. Quality of life and its assessment in multiple sclerosis: integrating physical and psychological components of wellbeing. Lancet Neurol. 2005;4:9.

10. Sadovnick AD, Remick RA, Allen J, et al. Depression and multiple sclerosis. Neurology. 1996;46:628-632.

11. Garcia de Alba Garcia JE, Dallo FJ, Salcedo Rocha AL, et al. The relative effect of self-management practices on glycaemic control in type 2 diabetic patients in Mexico. Chronic Illness. 2006;2:77-85.

12. van den Noort S, Holland NJ. Multiple Sclerosis in Clinical Practice. New York, NY: Demos Publishing; 1999: 1.

13. Braden CJ. Learned self-help response to chronic illness. Sch Inq Nurs Pract. 1990;4:23-41.

14. Terry DJ. Stress, coping and adaptation to new parenthood. J Soc Pers Relat. 1991;8:527-547.

15. Rigby SA, Domenech C, Thorton EW, Tedman S, Young CA. Development and validation of a self-efficacy measure for people with multiple sclerosis: the Multiple Sclerosis Self-Efficacy Scale. Mult Scler. 2003;9:73-81

16. Hoyl MT, Alessi CA, Harker JO, et al. Development and testing of a five-item version of the Geriatric Depression Scale. J Am Geriatr Soc. 1999;47:873-878.

17. Sidani S. Therapeutic Self-Care Tool Guidelines for Use. Toronto, Canada: University of Toronto; 2001.

18. Polman $\mathrm{CH}$, Reingold SC, Edan G, et al. Diagnostic criteria for multiple sclerosis: 2005 revisions to the "McDonald Criteria." Ann Neurol. 2005;58:840-846.

19. Baron RM, Kenny DA. The moderator-mediator variable distinction in social psychological research: conceptual, strategic, and statistical considerations. J Pers Soc Psychol. 1986;51:1173-1182.

20. Hohol M, Orav EJ, Weiner HL. Disease steps in multiple sclerosis: a simple approach to evaluate disease progression. Neurology. 1995; 45:251-255.

21. Tribe K, Longley WA, Fulcher G, et al. Living with multiple sclerosis in New South Wales, Australia, at the beginning of the 21 st century: impact of mobility disability. Int J MS Care. 2006;8:19-30.

22. Marrie RA, Cutter G, Tyry T, Vollmer T, Campagnolo D. Does multiple sclerosis-associated disability differ between races? Neurology. 2006;66:1235-1240.

23. Chalfant AM, Bryant RA, Fulcher G. PTSD following diagnosis of MS. J Trauma Stress. 2004; 17:423-428.

24. Sheikh JI, Yesavage J. Geriatric Depression Scale (GDS): recent evidence and development of a shorter version. Clin Gerontol. 1986:5.

25. Lelito RH, Palumbo LO, Hanley M. Psychometric evaluation of a brief geriatric depression screen. Aging Ment Health. 2000;5:387-393.

26. Skevington SM, Bradshaw J, Hepplewhite A, Dawkes K, Levell CR. How does psoriasis affect quality of life? assessing an Ingram-regimen outpatient programme and validating the WHOQOL-100. Br J Dermatol. 2005; 154:680-691.
27. Masthoff ED, Trompenaars FJ, Van Heck GL, Hodiamont PP, De Vries J. Validation of the WHO Quality of Life assessment instrument (WHOQOL-100) in a population of Dutch adult psychiatric outpatients. Eur Psychiatry. 2005;20:465-473.

28. The WHOQOL Group: The World Health Organization Quality of Life Assessment (WHOQOL): development and general psychometric properties. Soc Sci Med. 1998;46:1569-1585.

29. Trisolini M, Weiner J, Miller D. Principles to Promote Quality of Life in People with MS. London: Multiple Sclerosis International Federation. http://www.ms-in-europe.com/w3p_dokumentearchiv/6qualityof life08.pdf. Accessed April 3, 2010.

30. Doran DI, Sidani S, Keatings M, Doidge D. An empirical test of the nursing role effectiveness model. J Adv Nurs. 2002;38:29-39.

31. Orton SM, Herrera BM, Yee IM, et al. Sex ratio of multiple sclerosis in Canada: a longitudinal study. Lancet Neurol. 2006;5:932-936.

32. Hirst C, Ingram G, Pickersgill T, Swingler R, Compston DA, Robertson NP. Increasing prevalence and incidence of multiple sclerosis in South East Wales. J Neurol Neurosurg Psychiatry. 2009;80:386-391.

33. Simmons RD, Carroll W, King J, et al. Update on the Australian MS Longitudinal Study. ICODIMS Platform Presentation, Consortium of Multiple Sclerosis Centers; May 30, 2003; Chicago, IL.

34. Confavreux C, Vukusic S, Moreau T, Adeleine P. Relapses and progression of disability in multiple sclerosis. N Engl J Med. 2000; 16:343.

35. Fraser C, Polito S. A comparative study of self-efficacy in men and women with multiple sclerosis. J Neurosci Nurs. 2007;39:102-106.

36. Kralik D, Koch T, Price K, Howard N. Chronic illness self-management: taking action to create order. J Clin Nurs. 2004;13:259-267.

37. Kopke S, Kasper J, Muhlhauser I, Nubling M, Heesen C. Patient education program to enhance decision autonomy in multiple sclerosis relapse management: a randomized-controlled trial. Mult Scler. 2009; 15:96-104.

38. Shaw C, Logan K, Webber I, Broome L, Samuel S. Effect of clean intermittent self-catheterization on quality of life: a qualitative study. J Adv Nurs. 2008;61:641-650.

39. Chiovetti A. Bridging the gap between health literacy and patient education for people with multiple sclerosis. J Neurosci Nurs. 2006;8:374-378.

40. Kralik D. Poodle skirts, lava lamps and hot pants ... is chronic condition self-management another fad? J Adv Nurs. 2008;62:2.

41. Turpin KVL, Carroll L, Cassidy JD, Hader WJ. Deterioration in the health-related quality of life of persons with multiple sclerosis: the possible warning signs. Mult Scler. 2007; 13:1038-1045.

42. Koch LC, Rumrill PD, Roessler RT, Fitzgerald S. Illness and demographic correlates of quality of life among people with multiple sclerosis. Rehabil Psychol. 2007;46:154-164.

43. Gulick EE. Correlates of quality of life among persons with multiple sclerosis. Nurs Res. 1997;46:305-311.

44. Mohr DC, Goodkin DE. Treatment of depression in multiple sclerosis: review and meta-analysis. Clin Psychol Sci Pract. 1999;6:1-9.

45. Malcomson KS, Lowe-Strong AS, Dunwoody L. What can we learn from the personal insights of individuals living and coping with multiple sclerosis? Disabil Rehabil. 2008;30:662-674. 